\title{
Effects of the Japanese Stock Market on Canadian Value Stocks
}

\author{
Chikashi Tsuji ${ }^{1}$ \\ ${ }^{1}$ Faculty of Economics, Chuo University, Tokyo, Japan \\ Correspondence: Chikashi Tsuji, Professor, Faculty of Economics, Chuo University, 742-1 Higashinakano, \\ Hachioji-shi, Tokyo 192-0393, Japan. Tel: 81-42-674-2211. E-mail: mail_sec_low@minos.ocn.ne.jp
}

Received: March 10, 2016

Accepted: April 1, 2016

Online Published: April 22, 2016

doi:10.5430/jms.v7n2p21

URL: http://dx.doi.org/10.5430/jms.v7n2p21

\begin{abstract}
This paper empirically examines the time-series relationships of value, growth, and standard stock indices in Canadian and Japanese equity markets. More specifically, we investigate the effects of the returns of the Nikkei 225 (the Nikkei), Tokyo stock price index (TOPIX), and Japanese value and growth stock indices on Canadian value, growth, and standard equity index returns. The new evidence from our empirical examinations is as follows. 1) First, our analyses by the exponential generalized autoregressive conditional heteroscedasticity (EGARCH) models find that the returns of the Nikkei and TOPIX most strongly influence value stock index returns in Canada. 2) Second, our examinations by the EGARCH models clarify that the Japanese value and growth equity index return evolution also most strongly affects Canadian value stock returns.
\end{abstract}

Keywords: EGARCH model, growth stocks, stock market linkage, value stocks

\section{Introduction}

Many past researches have paid attention to the issues of the international equity market linkage (e.g., Ratanapakorn and Sharma, 2002; Chien et al., 2015) and the value and growth stock performances (e.g., Bauman et al., 1998; Fama and French, 2006; Gharghori et al., 2013; Chung et al., 2016). However, it is considered that these issues have been segmentedly researched; thus, for attempting more advanced contribution to the body of research in finance and economics, this paper newly performs a combined study of these two topics by using value, growth, and standard stock index data from Canadian and Japanese stock markets. Based on the motivation documented above, we analyze four kinds of Japanese stock index returns and three kinds of Canadian equity index returns. More concretely, we empirically test the international effects of returns of the Nikkei 225 (the Nikkei), Tokyo stock price index (TOPIX), and Japanese value and growth stock indices on returns of value, growth, and standard stock indices of Canada. All index data except for the Nikkei and TOPIX are Morgan Stanley Capital International (MSCI) index data.

As a result of our empirical examinations by using the exponential generalized autoregressive conditional heteroscedasticity (EGARCH) models, we derive the following interesting new findings. First, 1) our analyses by the EGARCH models find that the returns of the Nikkei and TOPIX most strongly influence value stock index returns in Canada. Second, 2) our examinations by the EGARCH models further clarify that the Japanese value and growth stock index return evolution also most strongly affects Canadian value stock returns.

We organize the remainder of the paper as follows. First, in Section 2, we review previous studies. In Section 3, we describe our data and then in Section 4, we document our econometric methodology. We then report our empirical results in Section 5 and Section 6 concludes the paper.

\section{Literature Review}

First, regarding the research of relationships among international stock markets, there are many existing studies with respect to the simple connections among international stock markets. Briefly reviewing recent studies, Tsai (2014) investigated the spillover effects by using standard equity index returns of stock markets in the US, UK, Germany, France, and Japan. Moreover, also by using standard stock index data, Vu (2015) studied the outputs' reactions to the volatility of stock markets for 27 countries. Further, Guidi and Ugur (2014) analyzed South Eastern European stock markets by focusing on the cointegrating relations and portfolio diversification benefits.

Next, as for the researches of growth and value stocks, the value effects have been much more investigated than the growth effects. For example, Liu and Zhang (2008) analyzed the value spreads in the US, and this paper concluded 
that in the United States, the value spreads seemed to be much less effective for forecasting stock returns. Further, Baltussen et al. (2012) studied the US stock market and suggested that the value premiums were smaller for such investors as insurance companies and pension funds, especially when they are downside risk averse. Moreover, Fong (2012) reexamined the value effects in the US and suggested that none of the test results in this study supplied robust evidence that business risk could explain the value premiums.

Contrary to the value effects, there is little research that investigated the growth effects. A study by Rytchkov (2010) explored the return predictability regarding US growth and value portfolios. This study suggested that returns of growth and value portfolios in the US were predictable and the predictability was stronger for growth portfolios than for value portfolios. Moreover, Larsen and Munk (2012) tested whether the value/growth tilting strategies are effective in the dynamic asset allocation framework, and their results suggested that the value/growth tilting strategies were rather effective. Further, applying econometric methodology, Tsuji (2007) searched for macroeconomic factors that were priced in the stock market in Japan; and Tsuji (2012) explored the small-size- and value-premia in Japan. However, their studies' focuses were not on the international stock market connections.

Table 1. Descriptive statistics of the daily log percentage returns in terms of equity indices in Canada and Japan

\begin{tabular}{lcc}
\hline Panel A. Statistics of Japanese equity indices & \\
\hline Mean & DLNK & DLTPX \\
Median & 0.0105 & 0.0042 \\
Maximum & 0.0451 & 0.0444 \\
Minimum & 13.2346 & 12.8647 \\
Standard deviation & -12.1110 & -10.0071 \\
Skewness & 1.5613 & 1.4175 \\
Kurtosis & -0.4659 & -0.3922 \\
Observations & 9.5578 & 9.2869 \\
& 3,306 & 3,306 \\
\hline Mean & DLJG & DLJV \\
Median & 0.0044 & 0.0160 \\
Maximum & 0.0278 & 0.0496 \\
Minimum & 13.1060 & 13.0199 \\
Standard deviation & -10.8347 & -10.2409 \\
Skewness & 1.5016 & 1.4328 \\
Kurtosis & -0.3527 & -0.3558 \\
Observations & 8.5573 & 9.4570 \\
\hline Pan B. Stastics & 3,306 & 3,306 \\
\hline
\end{tabular}

Panel B. Statistics of Canadian equity indices

\begin{tabular}{lccc}
\hline & DLCA & DLCAG & DLCAV \\
\hline Mean & 0.0290 & 0.0269 & 0.0302 \\
Median & 0.0630 & 0.0440 & 0.0507 \\
Maximum & 9.7245 & 10.3933 & 10.0484 \\
Minimum & -10.4025 & -11.9663 & -10.3978 \\
Standard deviation & 1.1688 & 1.3521 & 1.1234 \\
Skewness & -0.6030 & -0.7009 & -0.3116 \\
Kurtosis & 13.5813 & 14.0310 & 13.6538 \\
Observations & 3,306 & 3,306 & 3,306 \\
\hline
\end{tabular}

Notes: This table presents the descriptive statistics for Japanese and Canadian stock index returns. Our sample period is from 21 June 2001 to 5 December 2014. 
Panel A. DLNK

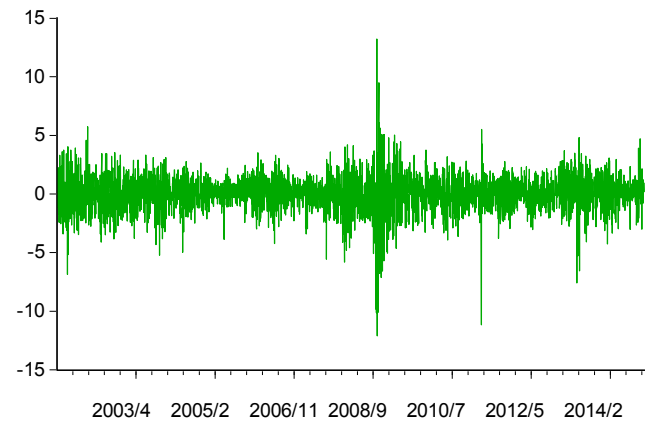

Panel C. DLJG

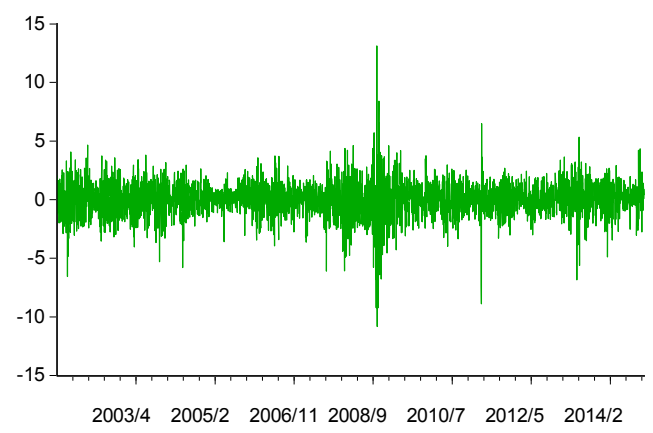

Panel E. DLCA

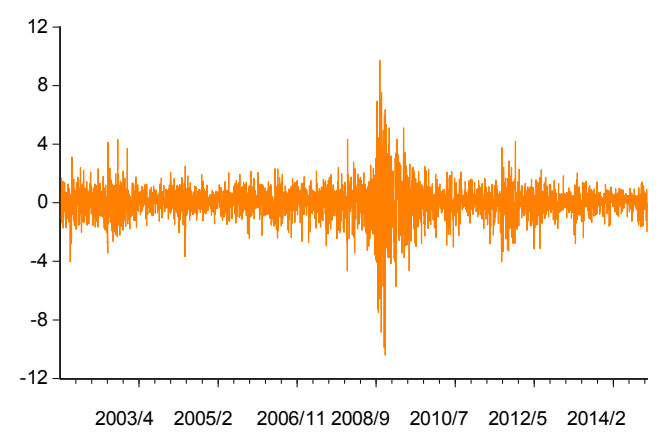

Panel B. DLTPX

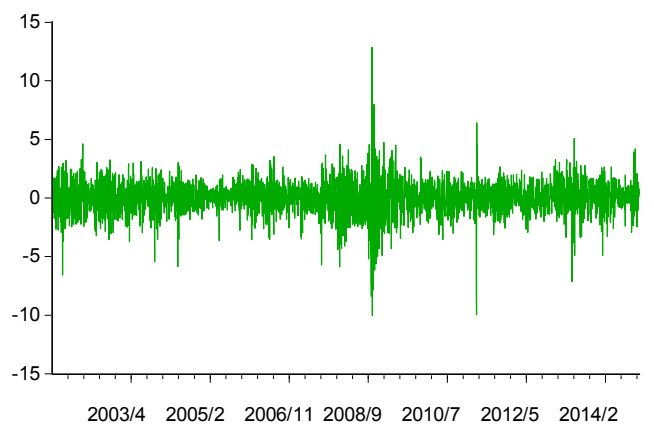

Panel D. DLJV

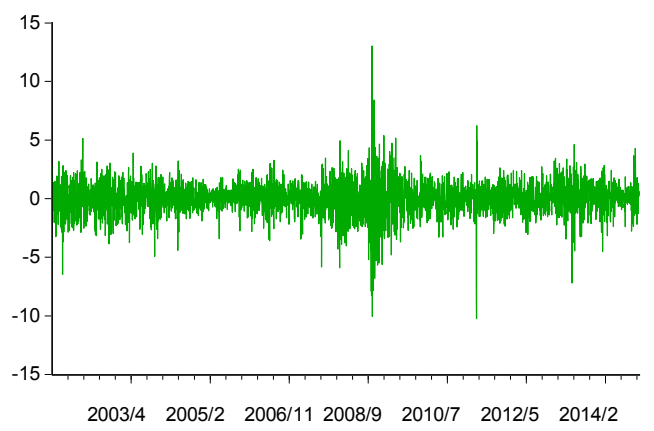

Panel F. DLCAG

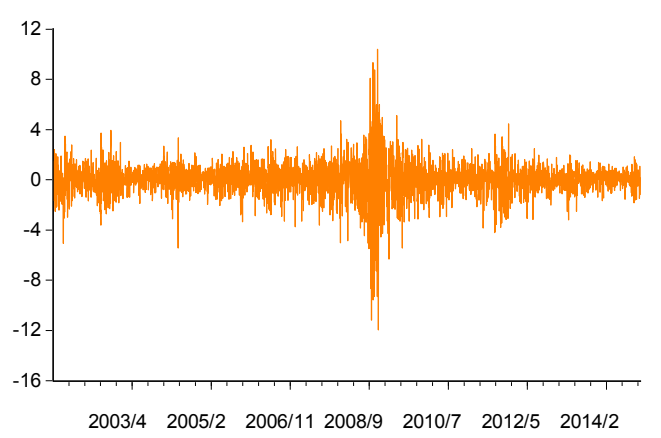

Panel G. DLCAV

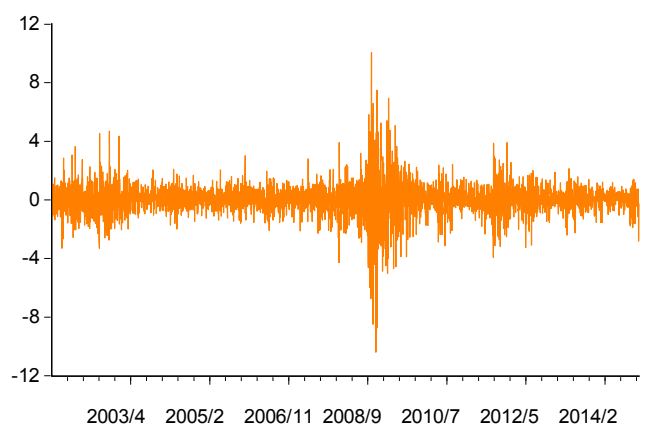

Figure 1. Time-series of daily percentage log returns of Canadian and Japanese equity indices: For the period from 21 June 2001 to 5 December 2014 


\section{Data}

In our research, we use four Japanese and three Canadian equity index data. The full sample period of our daily data is from 21 June 2001 to 5 December 2014. All data investigated in this study are supplied by the QUICK Corp. and the number of our time-series observations of each equity index is 3,306. Specifically, as regards Japan, DLNK means the daily percentage log return as to the Nikkei 225 stock index; DLTPX represents that of TOPIX; DLJG means the daily percentage log return as to the MSCI Japanese growth equity index; and DLJV represents that of the MSCI Japanese value equity index. As for Canadian stock markets, DLCA represents the daily percentage log return as to the MSCI Canadian standard equity index; DLCAG denotes that of the MSCI Canadian growth equity index; and DLCAV is that of the MSCI Canadian value equity index. Analyzing these data, we investigate the international effects of the time-series return evolution of the Japanese growth, value, and standard stock indices on the Canadian value, growth, and standard equity index returns. Figure 1 displays the time-series of the above seven returns. Table 1 displays the descriptive statistics for these seven time-series variables. Documenting some characteristics of the variables, Japanese stock index returns are somewhat more volatile than Canadian stock index returns. Further, Canadian stock index returns exhibit slightly higher kurtosis values than those of Japanese stock index returns.

\section{Method}

For testing the international effects of Japanese stock index returns on the MSCI Canadian value, growth, and standard stock index returns, we employ a GARCH model, whose mean equation includes autoregressive (AR) terms. Specifically, we employ the following AR(5)-EGARCH model with generalized error distribution (GED) errors to investigate the effects of the four kinds of Japanese equity index returns on the three Canadian stock index returns:

$$
\begin{aligned}
& \operatorname{can}_{t}=\mu_{1}+\mu_{2} j p_{t}+\sum_{p=1}^{5} \phi_{p} \operatorname{can}_{t-p}+\varepsilon_{t}, \\
& \ln \left(\sigma_{t}^{2}\right)=\xi_{1}+\xi_{2} \ln \left(\sigma_{t-1}^{2}\right)+\xi_{3}\left|\varepsilon_{t-1} / \sigma_{t-1}\right|+\xi_{4}\left(\varepsilon_{t-1} / \sigma_{t-1}\right),
\end{aligned}
$$

where $j p_{t}$ means one of the Japanese equity index returns and $\mathrm{can}_{t}$ means one of the Canadian equity index returns. Using the above model (1), we empirically examine the effects of returns of the Japanese equity indices such as TOPIX, the Nikkei, MSCI Japanese value, and MSCI Japanese growth stock indices on returns of the MSCI Canadian standard, value, and growth equity indices. It is noted that there is about 14-hour time difference between Tokyo and Toronto; thus, the Japanese equity market is ahead of the Canadian stock market. Hence, we analyze the same day data of Canadian and Japanese equity indices. By this analysis, we can evaluate the time-series effects of the Japanese stock market on the succeeding Canadian stock market.

\section{Empirical Results}

Empirical results from our investigations are displayed in Tables 2 to 5. First, Table 2 shows the effects of the Nikkei on Canadian stock markets and Table 3 exhibits those of TOPIX on Canadian stock markets. Describing important points concisely, both in Tables 2 and 3, all estimated coefficients of the daily returns as to the Nikkei and TOPIX are statistically significantly positive. These results indicate that the preceding time-series fluctuations of the Nikkei and TOPIX substantially influence the succeeding time-series evolution of not only the value and growth equity returns but also the overall equity market returns in Canada. Moreover, the smallest values of both the Akaike's information criterion (AIC) and the Schwartz (information) criterion (SC) are found in Panel C in Table 2. This suggests that the Nikkei most strongly affects the succeeding time-series evolution of the value stock index in Canada. In addition, in Table 3, we also find the smallest AIC and SC values in Panel C. Hence, these results again suggest that TOPIX changes also have the greatest effect on the succeeding time-series of the value stock index returns in Canada.

Next, Table 4 shows the effects of the returns of the Japanese growth stock index on Canadian stock markets and Table 5 exhibits those of the Japanese value equity index on Canadian stock markets. Specifically, both in Tables 4 and 5, all estimated coefficients of the daily returns as to the Japanese growth and value equity index returns are statistically significantly positive. Thus, these results suggest that the preceding time-series changes of the Japanese growth and value stock index returns strongly affect the following time-series changes of growth, value, and overall equity market indices in Canada. Moreover, in Table 4, the smallest values of AIC and SC are seen in Panel C. This evidence means that the Japanese growth equity index returns most substantially affect the following time-series of the Canadian value index returns. Furthermore, in Table 5, it is found that the smallest values of AIC and SC are seen in Panel C. Hence, the results mean that for Canadian stock markets, the preceding Japanese value stock index returns also have the strongest effect on the value stock index returns. 
Table 2. Effects of the Nikkei 225 on Canadian stock markets: Results of the AR(5)-EGARCH models with the GED errors

\begin{tabular}{|c|c|c|}
\hline \multicolumn{3}{|c|}{ Mean equation } \\
\hline Variables & Coefficients & $p$-value \\
\hline Intercept & $0.0544 * * *$ & 0.0000 \\
\hline DLNK & $0.1232 * * *$ & 0.0000 \\
\hline $\operatorname{AR}(1)$ & $-0.0829 * * *$ & 0.0000 \\
\hline $\operatorname{AR}(2)$ & -0.0270 & 0.1201 \\
\hline $\operatorname{AR}(3)$ & $-0.0320 *$ & 0.0610 \\
\hline $\operatorname{AR}(4)$ & -0.0228 & 0.1841 \\
\hline $\operatorname{AR}(5)$ & -0.0212 & 0.2073 \\
\hline \multicolumn{3}{|c|}{ Model statistics } \\
\hline $\mathrm{AIC}$ & 2.592624 & \\
\hline $\mathrm{SC}$ & 2.614806 & \\
\hline \multicolumn{3}{|c|}{ Panel B. Effects of the Nikkei 225 on the Canadian growth equity index } \\
\hline \multicolumn{3}{|c|}{ Mean equation } \\
\hline Variables & Coefficients & $p$-value \\
\hline Intercept & $0.0534 * * *$ & 0.0001 \\
\hline DLNK & $0.1222 * * *$ & 0.0000 \\
\hline $\operatorname{AR}(1)$ & $-0.0585 * * *$ & 0.0012 \\
\hline $\mathrm{AR}(2)$ & -0.0191 & 0.2736 \\
\hline $\operatorname{AR}(3)$ & $-0.0293 *$ & 0.0880 \\
\hline $\operatorname{AR}(4)$ & -0.0105 & 0.5466 \\
\hline $\operatorname{AR}(5)$ & -0.0140 & 0.4120 \\
\hline \multicolumn{3}{|c|}{ Model statistics } \\
\hline $\mathrm{AIC}$ & 2.887156 & \\
\hline $\mathrm{SC}$ & 2.909339 & \\
\hline
\end{tabular}

Panel C. Effects of the Nikkei 225 on the Canadian value equity index

\begin{tabular}{lll}
\hline Mean equation & & \\
\hline Variables & Coefficients & $p$-value \\
\hline Intercept & $0.0508^{* * *}$ & 0.0000 \\
DLNK & $0.1157^{* * *}$ & 0.0000 \\
AR(1) & $-0.0804^{* * *}$ & 0.0000 \\
AR(2) & -0.0220 & 0.1998 \\
AR(3) & -0.0192 & 0.2636 \\
AR(4) & -0.0244 & 0.1511 \\
AR(5) & $-0.0297 *$ & 0.0776 \\
\hline Model statistics & & \\
\hline AIC & 2.481026 & \\
SC & 2.503208 & \\
\hline
\end{tabular}

Notes: This table presents the estimation results of the various EGARCH models, which are specified for examining the effects of the Nikkei 225 stock index on the value, growth, and standard stock indices of Canada. In this table, AIC represents the Akaike's information criterion and SC denotes the Schwartz information criterion. Further, ***, $* *$, and $*$ mean the statistical significance of the coefficients at the $1 \%, 5 \%$, and $10 \%$ levels, respectively. 
Table 3. Effects of the TOPIX on Canadian stock markets: Results of the AR(5)-EGARCH models with the GED errors

\begin{tabular}{|c|c|c|}
\hline \multicolumn{3}{|c|}{ Mean equation } \\
\hline Variables & Coefficients & $p$-value \\
\hline Intercept & $0.0538 * * *$ & 0.0000 \\
\hline DLTPX & $0.1390 * * *$ & 0.0000 \\
\hline $\mathrm{AR}(1)$ & $-0.0837 * * *$ & 0.0000 \\
\hline $\operatorname{AR}(2)$ & $-0.0289 *$ & 0.0962 \\
\hline $\operatorname{AR}(3)$ & $-0.0296^{*}$ & 0.0826 \\
\hline $\operatorname{AR}(4)$ & -0.0210 & 0.2220 \\
\hline $\operatorname{AR}(5)$ & -0.0187 & 0.2663 \\
\hline \multicolumn{3}{|c|}{ Model statistics } \\
\hline AIC & 2.591224 & \\
\hline $\mathrm{SC}$ & 2.613406 & \\
\hline \multicolumn{3}{|c|}{ Panel B. Effects of the TOPIX on the Canadian growth equity index } \\
\hline \multicolumn{3}{|c|}{ Mean equation } \\
\hline Variables & Coefficients & $p$-value \\
\hline Intercept & $0.0526 * * *$ & 0.0001 \\
\hline DLTPX & $0.1363 * * *$ & 0.0000 \\
\hline $\operatorname{AR}(1)$ & $-0.0578 * * *$ & 0.0014 \\
\hline $\operatorname{AR}(2)$ & -0.0198 & 0.2550 \\
\hline $\operatorname{AR}(3)$ & -0.0264 & 0.1232 \\
\hline $\operatorname{AR}(4)$ & -0.0077 & 0.6574 \\
\hline $\operatorname{AR}(5)$ & -0.0122 & 0.4762 \\
\hline \multicolumn{3}{|c|}{ Model statistics } \\
\hline AIC & 2.886283 & \\
\hline $\mathrm{SC}$ & 2.908465 & \\
\hline
\end{tabular}

Panel C. Effects of the TOPIX on the Canadian value equity index

\begin{tabular}{lll}
\hline Mean equation & & \\
\hline Variables & Coefficients & $p$-value \\
\hline Intercept & $0.0508^{* * *}$ & 0.0000 \\
DLTPX & $0.1299^{* * *}$ & 0.0000 \\
AR(1) & $-0.0793^{* * *}$ & 0.0000 \\
AR(2) & -0.0255 & 0.1369 \\
AR(3) & -0.0188 & 0.2738 \\
AR(4) & -0.0224 & 0.1890 \\
AR(5) & -0.0275 & 0.1014 \\
\hline Model statistics & & \\
\hline AIC & 2.478891 & \\
SC & 2.501073 &
\end{tabular}

Notes: This table presents the estimation results of the various EGARCH models, which are specified for examining the effects of the TOPIX on the value, growth, and standard stock indices of Canada. In this table, AIC represents the Akaike's information criterion and SC denotes the Schwartz information criterion. Further, ${ }^{* * *}, * *$, and $*$ mean the statistical significance of the coefficients at the $1 \%, 5 \%$, and $10 \%$ levels, respectively. 
Table 4. Effects of the Japanese growth equity index on Canadian stock markets: Results of the AR(5)-EGARCH models with the GED errors

\begin{tabular}{lll}
\hline \multicolumn{2}{l}{ Panel A. Effects of the Japanese growth equity index on the Canadian standard equity index } \\
\hline Mean equation & & \\
\hline Variables & Coefficients & 0.0000 \\
\hline Intercept & $0.0535^{* * *}$ & 0.0000 \\
DLJG & $0.1297^{* * *}$ & 0.0000 \\
AR(1) & $-0.0842^{* * *}$ & 0.0916 \\
AR(2) & $-0.0293^{*}$ & 0.0600 \\
AR(3) & $-0.0321^{*}$ & 0.2485 \\
AR(4) & -0.0198 & 0.2529 \\
AR(5) & -0.0193 & \\
\hline Model statistics & & \\
\hline AIC & 2.591292 & \\
SC & 2.613474 & $p$-value \\
\hline Panel B. Effects of the Japanese growth & equity index on the Canadian growth equity index \\
\hline Mean equation & & 0.0001 \\
Variables & Coefficients & 0.0000 \\
\hline Intercept & $0.0517^{* * *}$ & 0.0009 \\
DLJG & $0.1282^{* * *}$ & 0.2524 \\
AR(1) & $-0.0600^{* * *}$ & 0.0879 \\
AR(2) & -0.0199 & 0.6370 \\
AR(3) & $-0.0293^{*}$ & 0.4381 \\
AR(4) & -0.0082 & \\
AR(5) & -0.0132 & \\
\hline Model statistics & & \\
\hline AIC & 2.886625 & \\
SC & 2.908807 & \\
\hline Pan & & \\
\hline
\end{tabular}

Panel C. Effects of the Japanese growth equity index on the Canadian value equity index

\begin{tabular}{lll}
\hline Mean equation & & \\
\hline Variables & Coefficients & $p$-value \\
\hline Intercept & $0.0502^{* * *}$ & 0.0000 \\
DLJG & $0.1207^{* * *}$ & 0.0000 \\
AR(1) & $-0.0795^{* * *}$ & 0.0000 \\
AR(2) & -0.0256 & 0.1361 \\
AR(3) & -0.0189 & 0.2702 \\
AR(4) & -0.0222 & 0.1945 \\
AR(5) & $-0.0295^{*}$ & 0.0799 \\
\hline Model statistics & & \\
\hline AIC & 2.479737 & \\
SC & 2.501919 & \\
\hline
\end{tabular}

Notes: This table presents the estimation results of the various EGARCH models, which are specified for examining the effects of the Japanese growth stock index on the value, growth, and standard stock indices of Canada. In this table, AIC represents the Akaike's information criterion and SC denotes the Schwartz information criterion. Further, $* * *, * *$, and $*$ mean the statistical significance of the coefficients at the $1 \%, 5 \%$, and $10 \%$ levels, respectively. 
Table 5. Effects of the Japanese value equity index on Canadian stock markets: Results of the AR(5)-EGARCH models with the GED errors

\begin{tabular}{|c|c|c|}
\hline \multicolumn{3}{|c|}{ Panel A. Effects of the Japanese value equity index on the Canadian standard equity index } \\
\hline \multicolumn{3}{|c|}{ Mean equation } \\
\hline Variables & Coefficients & $p$-value \\
\hline Intercept & $0.0518 * * *$ & 0.0000 \\
\hline DLJV & $0.1397 * * *$ & 0.0000 \\
\hline $\operatorname{AR}(1)$ & $-0.0817 * * *$ & 0.0000 \\
\hline $\mathrm{AR}(2)$ & -0.0250 & 0.1481 \\
\hline $\operatorname{AR}(3)$ & $-0.0283 *$ & 0.0960 \\
\hline $\mathrm{AR}(4)$ & -0.0190 & 0.2691 \\
\hline $\operatorname{AR}(5)$ & -0.0171 & 0.3108 \\
\hline \multicolumn{3}{|c|}{ Model statistics } \\
\hline AIC & 2.590413 & \\
\hline $\mathrm{SC}$ & 2.612595 & \\
\hline \multicolumn{3}{|c|}{ Panel B. Effects of the Japanese value equity index on the Canadian growth equity index } \\
\hline \multicolumn{3}{|c|}{ Mean equation } \\
\hline Variables & Coefficients & $p$-value \\
\hline Intercept & $0.0525 * * *$ & 0.0001 \\
\hline DLJV & $0.1372 * * *$ & 0.0000 \\
\hline $\mathrm{AR}(1)$ & $-0.0584 * * *$ & 0.0012 \\
\hline $\operatorname{AR}(2)$ & -0.0188 & 0.2778 \\
\hline $\operatorname{AR}(3)$ & -0.0246 & 0.1490 \\
\hline $\operatorname{AR}(4)$ & -0.0080 & 0.6447 \\
\hline $\operatorname{AR}(5)$ & -0.0116 & 0.4981 \\
\hline \multicolumn{3}{|c|}{ Model statistics } \\
\hline $\mathrm{AIC}$ & 2.885846 & \\
\hline $\mathrm{SC}$ & 2.908028 & \\
\hline
\end{tabular}

Panel C. Effects of the Japanese value equity index on the Canadian value equity index

\begin{tabular}{lll}
\hline Mean equation & & \\
\hline Variables & Coefficients & $p$-value \\
\hline Intercept & $0.0496^{* * *}$ & 0.0000 \\
DLJV & $0.1340^{* * *}$ & 0.0000 \\
AR(1) & $-0.0806^{* * *}$ & 0.0000 \\
AR(2) & -0.0266 & 0.1224 \\
AR(3) & -0.0178 & 0.3007 \\
AR(4) & -0.0214 & 0.2104 \\
AR(5) & -0.0260 & 0.1214 \\
\hline Model statistics & & \\
\hline AIC & 2.477291 & \\
SC & 2.499473 & \\
\hline
\end{tabular}

Notes: This table presents the estimation results of the various EGARCH models, which are specified for examining the effects of the Japanese value stock index on the value, growth, and standard stock indices of Canada. In this table, AIC represents the Akaike's information criterion and SC denotes the Schwartz information criterion. Further, ***, ${ }^{* *}$, and ${ }^{*}$ mean the statistical significance of the coefficients at the $1 \%, 5 \%$, and $10 \%$ levels, respectively. 


\section{Conclusions}

This paper empirically examined the time-series relationships of growth, value, and standard stock indices in Canadian and Japanese equity markets. Specifically, we investigated the effects of TOPIX, the Nikkei 225, and Japanese value and growth stock indices on growth, value, and standard equity indices of Canada. The interesting findings we derived from our empirical examinations are as follows. 1) First, our analyses by the EGARCH models found that the Nikkei and TOPIX most strongly influenced the value stock index in Canada. 2) Second, our examinations by the EGARCH models clarified that the Japanese value and growth equity index return evolution also most strongly affected Canadian value stocks.

It is surprising that not the same-type stock indices but the different sorts of equity indices of Canada and Japan demonstrated tighter linkages. The evidence that various Japanese equity index returns analyzed in this paper were strongly connected with Canadian value stock returns was consistent and robust. We also note that our new approach to investigating the different kinds of stock indices in international stock markets shall add additional novel viewpoints not only to the existing body of literature but also to the future research as to the international stock market linkage. Further empirical study by employing other different international equity indices with other analyzing angles shall be also our future work.

\section{Acknowledgements}

The author is particularly grateful to the kind repeated invitation from the journal to write to this journal. I also appreciate the Japan Society for the Promotion of Science for their generous financial assistance to this research. Further, I thank the anonymous reviewers for their kind comments on this paper. Finally, I deeply thank all the Editors of this journal and Jenny Zhang for their kindness to this paper.

\section{References}

Baltussen, G., Post, G. T., \& Vliet, P. V. (2012). Downside risk aversion, fixed-income exposure, and the value premium puzzle. Journal of Banking \& Finance, 36, 3382-3398. http://dx.doi.org/10.2139/ssrn.1343018

Bauman, W. S., Conover, C. M., \& Miller, R. E. (1998). Growth versus value and large-cap versus small-cap stocks in international markets. Financial Analysts Journal, 54, 75-89. http://dx.doi.org/10.2469/faj.v54.n2.2168

Chien, M. S., Lee, C. C., Hu, T. C., \& Hu, H. T. (2015). Dynamic Asian stock market convergence: Evidence from dynamic cointegration analysis among China and ASEAN-5. Economic Modelling, 51, 84-98. http://dx.doi.org/10.1016/j.econmod.2015.06.024

Chung, Y. T., Hsu, C. H., Ke, M. C., Liao, T. L., \& Chiang, Y. C. (2016). The weakening value premium in the Australian and New Zealand stock markets. Pacific-Basin Finance Journal, 36, 123-133. http://dx.doi.org/10.1016/j.pacfin.2015.12.007

Fama, E. F., \& French, K. R. (2006). The value premium and the CAPM. Journal of Finance, 61, 2163-2185. http://dx.doi.org/10.1111/j.1540-6261.2006.01054.x

Fong, W. M. (2012). Do expected business conditions explain the value premium? Journal of Financial Markets, 15, 181-206. http://dx.doi.org/10.1016/j.finmar.2011.08.004

Gharghori, P., Stryjkowski, S., \& Veeraraghavan, M. (2013). Value versus growth: Australian evidence. Accounting \& Finance, 53, 393-417. http://dx.doi.org/10.1111/j.1467-629X.2012.00474.x

Guidi, F., \& Ugur, M. (2014). An analysis of South-Eastern European stock markets: Evidence on cointegration and portfolio diversification benefits. Journal of International Financial Markets, Institutions \& Money, 30, 119-136. http://dx.doi.org/10.1016/j.intfin.2014.01.007

Larsen, L. S., \& Munk, C. (2012). The costs of suboptimal dynamic asset allocation: General results and applications to interest rate risk, stock volatility risk, and growth/value tilts. Journal of Economic Dynamics \& Control, 36, 266-293. http://dx.doi.org/10.1016/j.jedc.2011.09.009

Liu, N., \& Zhang, L. (2008). Is the value spread a useful predictor of returns? Journal of Financial Markets, 11, 199-227. http://dx.doi.org/10.1016/j.finmar.2008.01.003

Ratanapakorn, O., \& Sharma, S. C. (2002). Interrelationships among regional stock indices. Review of Financial Economics, 11, 91-108. http://dx.doi.org/10.1016/S1059-0560(02)00103-X

Rytchkov, O. (2010). Expected returns on value, growth, and HML. Journal of Empirical Finance, 17, 552-565. http://dx.doi.org/10.1016/j.jempfin.2010.04.003 
Tsai, I. C. (2014). Spillover of fear: Evidence from the stock markets of five developed countries. International Review of Financial Analysis, 33, 281-288. http://dx.doi.org/10.1016/j.irfa.2014.03.007

Tsuji, C. (2007). What macro-innovation risks really are priced in Japan? Applied Financial Economics, 17, 1085-1099. http://dx.doi.org/10.1080/09603100600749345

Tsuji, C. (2012). Positive return premia in Japan. Quantitative Finance, 12, 345-367. http://dx.doi.org/10.1080/14697688.2010.541485

Vu, N. T. (2015). Stock market volatility and international business cycle dynamics: Evidence from OECD economies. Journal of International Money and Finance, 50, 1-15. http://dx.doi.org/10.1016/j.jimonfin.2014.08.003 